\title{
Wind speed description and power density in northern Spain
}

\author{
Cristina Herrero-Novoa, Isidro A. Pérez*, M. Luisa Sánchez, Mª Ángeles García, \\ Nuria Pardo, Beatriz Fernández-Duque
}

Department of Applied Physics, Faculty of Sciences, University of Valladolid, Paseo de Belén, 7, 47011 Valladolid, Spain

\section{A R T I C L E I N F O}

\section{Article history:}

Received 5 May 2017

Received in revised form

17 July 2017

Accepted 19 July 2017

Available online 24 July 2017

\section{Keywords:}

Wind statistics

Weibull distribution

Correlation

Surface distribution

\begin{abstract}
A B S T R A C T
Wind resources are increasingly being investigated as a clean alternative for generating energy. This paper analyses the daily wind speed recorded at 46 automatic weather stations located in Navarre, northern Spain, in 2005-2015. Key points are the surface density of stations and the range of time that ensure a faithful depiction of wind speed together with surface calculations from image analysis and correlation with height. Different statistics were used. Median wind speed at $10 \mathrm{~m}$ was low, about $3.3 \mathrm{~m} \mathrm{~s}^{-1}$ and its interquartile range was narrow, about $2.3 \mathrm{~m} \mathrm{~s}^{-1}$. Nearly half the surface shows a median wind speed above $3.0 \mathrm{~m} \mathrm{~s}^{-1}$. The method of moments was employed to calculate the parameters of the Weibull distribution. Around half of the surface presented a shape parameter above 2.25 and the scale parameter was above $4 \mathrm{~m} \mathrm{~s}^{-1}$ for nearly $41 \%$ of the region. Although wind resources are not suitable for wind turbine applications in most of the region, since the wind speed is low in low-lying areas, about $12 \%$ of the region is suitable for stand-alone applications and, moreover, a substantial part of the region, around $23 \%$, presents satisfactory wind resources for the installation of wind turbines.
\end{abstract}

(c) 2017 Elsevier Ltd. All rights reserved.

\section{Introduction}

Global development depends strongly on both the production and use of huge amounts of energy. Until a few years ago, this energy was mainly obtained from fossil fuels. However, awareness that such reserves are limited, coupled with the adverse consequences of their use on air pollution and climate change associated with carbon dioxide emissions, have intensified the search for alternative sources [1]. In Spain, the share of renewable energy sources in electricity generation was $40.8 \%$ in 2016 [2].

One prominent renewable energy source is wind power. A search for the term "wind power" in Scopus in the period 2000-2016 provides nearly 50000 documents. Although the publication rate has increased considerably from 254 documents in 2000-5600 in 2016, this change was not evenly distributed over the interval, since three periods may be established. The first extends from 2000 to 2006, when the publication grew at a rate of around 145 documents per year. In the second period, the number of documents published in 2009 was over twice the number published in 2007. In the third period, 2010-2016, publication increased at a rate of around 160 documents per year. In terms of

\footnotetext{
* Corresponding author.

E-mail address: iaperez@fa1.uva.es (I.A. Pérez).
}

countries, China leads the way with nearly 12000 documents, followed by the USA with just under 8000 . Although the publication rate was initially higher in the USA, China overtook the USA in terms of the number of documents published in 2007. Since 2010, the publication rate has remained constant in the USA, although it increased in China until 2014.

By the end of 2014, the power from this source installed in Spain was estimated at almost $23000 \mathrm{MW}$, the second highest in the European Union, behind Germany, which exceeded 39000 MW. Moreover, scenarios for 2030 estimate that the power installed in Spain might reach between 35000 and 52500 MW. Almost all of these facilities will be located onshore, with the contribution of marine facilities to installed power being noticeably marginal since the number of such facilities is only expected to grow in the high 2030 scenario. However, some countries, such as the United Kingdom, Germany, France, the Netherlands, Denmark and Belgium will have thousands of MW in offshore installations following the central 2030 scenario [3].

This paper is divided into three sections. The first is devoted to a detailed description of wind speed. A precise knowledge of the daily and seasonal evolution of wind speed is required before a given location is chosen to install a wind power generator [4,5]. Although wind speed measurements are desirable, such values are sometimes not available due to a lack of measuring devices. In such 


$\begin{array}{ll}\text { Nomenclature } \\ \mathrm{a} & \text { slope of a linear regression } \\ \mathrm{b} & \text { intercept of a linear regression } \\ \mathrm{c} & \text { Weibull scale parameter } \\ \mathrm{e} & \text { number e } \\ \mathrm{f} & \text { probability density function } \\ \mathrm{g} & \text { gravity at the Earth's surface } \\ \mathrm{h} & \text { Height } \\ \mathrm{h}_{\mathrm{r}} & \text { reference height } \\ \mathrm{k} & \text { Weibull shape parameter } \\ \mathrm{n} & \text { number of observations } \\ \mathrm{p} & \text { air pressure } \\ \mathrm{p}_{\mathrm{r}} & \text { air pressure at sea level } \\ \mathrm{R} & \text { universal gas constant } \\ \mathrm{r} & \text { correlation coefficient } \\ \mathrm{T} & \text { absolute temperature } \\ \mathrm{T}_{\mathrm{r}} & \text { absolute temperature at sea level }\end{array}$

$\begin{array}{ll}\mathrm{v} & \text { wind speed } \\ \bar{v} & \text { mean wind speed } \\ \tilde{v} & \text { median wind speed } \\ \mathrm{v}_{\mathrm{i}} & \text { wind speed observation } \\ \mathrm{v}_{\mathrm{r}} & \text { wind speed measured at the reference height } \\ \mathrm{v}_{0.10} & \text { first decile of wind speed } \\ \mathrm{v}_{0.25} & \text { first quartile of wind speed } \\ \mathrm{v}_{0.75} & \text { third quartile of wind speed } \\ \mathrm{v}_{0.90} & \text { ninth decile of wind speed } \\ \text { WPD } & \text { wind power density } \\ \mathrm{y} & \text { dependent variable in a linear regression } \\ & \\ G r e e k & \text { symbols } \\ \alpha & \text { exponent of the power-law equation } \\ \Gamma & \text { gamma function } \\ \gamma & \text { environmental lapse rate } \\ \rho & \text { air density } \\ \sigma & \text { standard deviation of wind speed }\end{array}$

instances, computer simulations may help [6,7]. Indeed, not only are models being developed to predict horizontal wind speeds [8] but, in addition, the impact of climate change on the cost of wind energy is also being analysed [9].

Most of the observations are available in the current study. However, one direct way to simplify the vast amount of data is by using certain statistics. Calculating mean wind speed is commonplace when analysing energy potential [10,11], and another frequent statistic is the standard deviation [12]. However, both quantities are highly sensitive to outliers. Although Mohammadpour Penchach et al. obtained quartiles of wind speed [13] which are more resistant to "wild data", one original contribution the present study makes is to calculate robust statistics not only for location but also for spread, symmetry and flatness, these latter two scarcely having been investigated to date.

Distribution functions are another way to handle the vast amount of observations needed for satisfactory wind description, with the Weibull distribution often being used [14]. This distribution, which is sometimes deemed the best among distributions with only one shape parameter [15], is an asymmetric function described by two parameters. However, research into alternative distributions remains active in an effort to overcome its inconveniences. The inverse Weibull distribution is suitable for longtailed right-skewed data [16]. In addition, gamma and lognormal distributions are sometimes used [17], and the beta Sarhan-Zaindin modified Weibull [18], as well as the Birnbaum-Saunders distributions, have recently been introduced [19]. Varied probability density functions have sometimes been compared [20], and adding distributions was also considered, particularly for multimodal behaviour [21,22].

The second section of the current research focuses on the Weibull distribution parameters. Since various procedures may be followed when calculating these, certain papers compare the parameter values obtained by different methods [23]. The double logarithmic transformation of the cumulative distribution function is one of the simplest [24], while the maximum likelihood method is a commonly used technique [25]. The procedure selected, the method of moments, presents an intermediate level of complexity.

Finally, the calculation of wind power density is presented. This section focuses on three variables; wind speed, hub height and air density. High wind speed values are desirable for wind farm installation. In particular, high altitude sites are very promising locations for wind power generation [26], whereas regions with moderate winds can be suitable for other applications such as local consumption, water pumping and agricultural applications [27]. The present study establishes the areas appropriate for each application in the region studied. Moreover, the height of the wind turbine tower must be considered, since wind speed changes with height and measurements are not usually taken at the height of interest [28]. In this case, an intermediate height has been considered. Lastly, the change in air density with height is sometimes ignored [29]. This paper goes one step further by considering the relationship between wind density and height and also temperature, which few studies have taken into account.

Spatial analysis has been used in the three sections, since the topography may have a marked influence on wind speed [30]. However, one noticeable difference to previous studies is the calculation and representation of the surface where certain variables peak. This treatment allows the relationship between the orography and the variable considered, such as the wind statistic, the Weibull parameter or the wind power density, to be investigated. One important feature is that this calculation relies on measurements from meteorological stations and is not a GIS-based approach [31].

Key points of this study are the high spatial density of the stations used, which implies a detailed description of the magnitudes calculated, the wide temporal interval of the observations employed, analysis of the influence of height on the variables obtained, and the calculation of the surface area included in certain ranges of the variables presented.

\section{Materials and methods}

\subsection{Experimental description}

The area of study is the Navarre region, which covers some $10391 \mathrm{~km}^{2}$, and which is located in northern Spain, between the western end of the Pyrenees to the north and the Ebro river to the south, about $42^{\circ} \mathrm{N} 1^{\circ} \mathrm{W}$, Fig. 1(a). Its relief and geographical features evidence three clearly differentiated areas: firstly, the northern part, "La Montaña", (The Mountain), has a pronounced relief, since it is part of the Pyrenean and Cantabrian mountain ranges; secondly, the southern part, "La Ribera", with large plains and soft reliefs located in the Ebro river depression; and finally, 

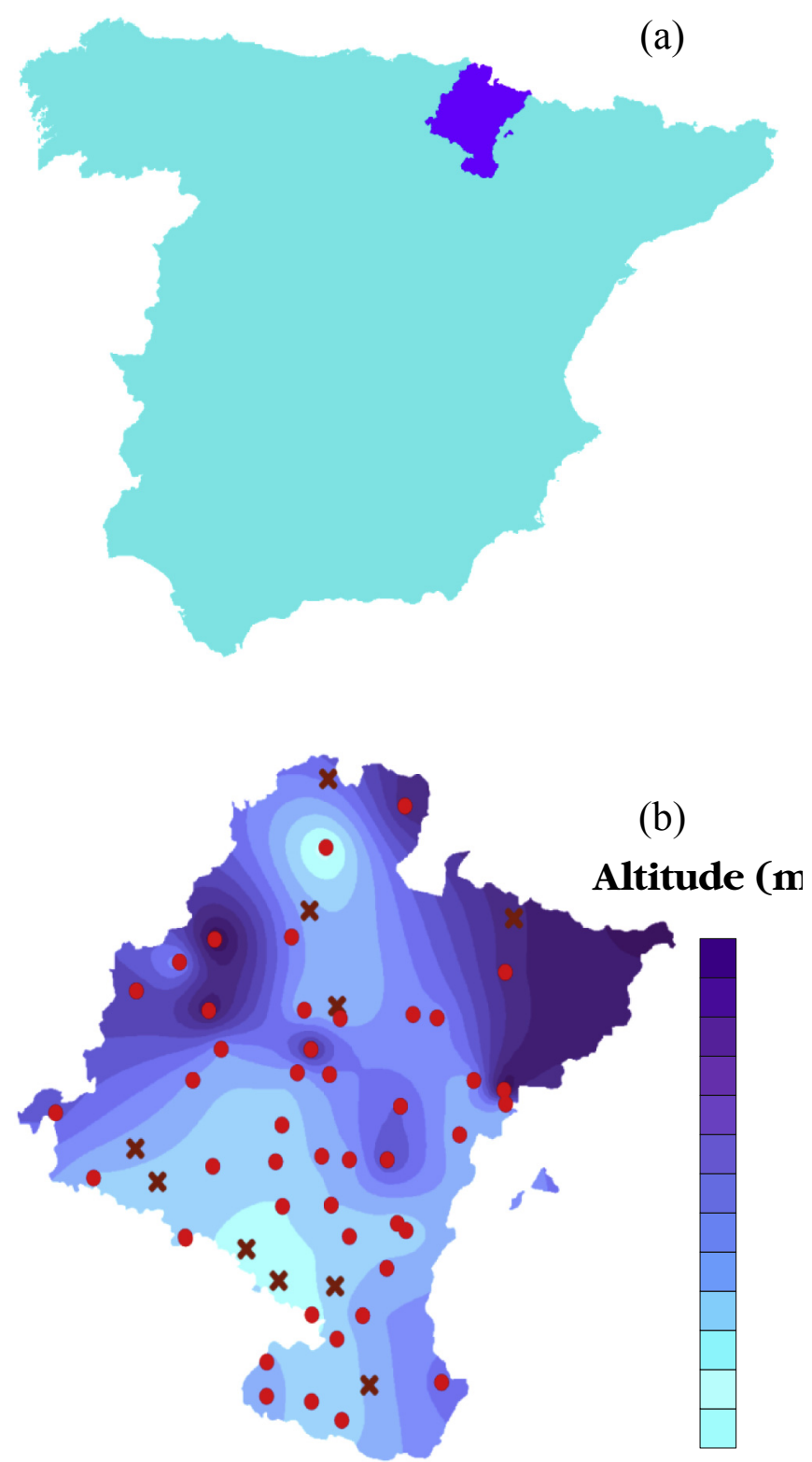

Fig. 1. (a) Location of the Navarre region in Spain. (b) Altitude map showing the distribution of automatic weather stations with dots. Discarded weather stations are indicated by crosses.

between these two areas lies the "Navarra Media", which shares features with the other two and is made up of plains, valleys and foothills, although these are higher than "La Ribera". Fig. 1(b) shows the relief of the region, following the preceding comments, although a noticeable low area is observed to the north.

Navarre has both manual and automatic weather stations. However, wind speed observations are only available at 56 automatic stations on the webpage of the regional government [32]. Information concerning certain features, such as altitude, longitude, latitude (both in UTM coordinates), ownership (agency on which it depends) and date of installation is presented for each weather station and datasets appear in annual files from the station start up. Different magnitudes are provided, although their number depends on the station. Wind speed observations are recorded daily at either $2 \mathrm{~m}$ or $10 \mathrm{~m}$ a.g.l. This study considers data from 2005 to 2015 . Four stations were discarded due to the short recording time or the absence of wind data, and a further six stations were also discarded since the number of available observations was below 85\%. The remaining 46 automatic weather stations are presented as dots in Fig. 1(b) where the discarded stations are marked with a cross. Although station density is noticeable, there is an area without stations to the north east. Consequently, values in this area are extrapolated and the closest stations will determine the values.

\subsection{Statistics}

Statistics are widely used in atmospheric observations. Some, such as the mean, standard deviation, and skewness or the kurtosis, are widely used. Unlike these conventional statistics, which are non-robust, since they are strongly influenced by outliers, other kinds of statistics, robust statistics, are resistant to possible anomalous data and less affected by outliers. Another advantage is that robust statistics are less sensitive to the shape of the data distribution than conventional statistics. This paper considers not only conventional statistics, but also robust statistics, such as the median, the interquartile range (i.e. the difference between the 3rd and 1st quartiles) and robust estimations for the skewness and kurtosis.

The robust skewness used in this study was Bowley's coefficient [33,34], sometimes called the Yule Kendall index [35],

Robust skewness $=\frac{v_{0.75}+v_{0.25}-2 \tilde{v}}{v_{0.75}-v_{0.25}}$,

where $\tilde{v}$ is the median wind and $v_{0.25}$ and $v_{0.75}$ are the 1 st and 3rd quartiles, respectively. Robust skewness lies between -1 and +1 , and its value is equal to zero for symmetrical distributions. Wind observations are typically right-skewed since the longest tail of the distribution is on the right.

Sachs [36] provided the following simple expression for the kurtosis

Robust Kurtosis $=\frac{v_{0.75}-v_{0.25}}{2\left(v_{0.90}-v_{0.10}\right)}$,

where $v_{0.10}$ and $v_{0.90}$ are the 1 st and 9th deciles respectively, with the value for the Gaussian distribution being 0.263 .

\subsection{Wind-speed variation with height}

Extrapolation is necessary to obtain wind speed data at heights where wind turbines are located, such as 40,50 or $90 \mathrm{~m}$, which are above the typical measurement height. The equation usually considered is the power law $[37,38]$

$v=v_{r}\left(\frac{h}{h_{r}}\right)^{\alpha}$

where $v_{r}$ is the wind speed measured at $h_{\mathrm{r}}, v$ the extrapolated wind speed at height $h$ and where the exponent $\alpha$ depends on surface roughness as well as atmospheric stability, its values ranging between 0.05 and 0.5 . In this study, a value of 0.145 was taken, which is similar to the frequently considered value $1 / 7$ and corresponds to countryside areas, where the weather stations are located, assuming neutral stability conditions, which are intermediate stability conditions. Under unstable conditions, $\alpha$ is low, 0.10 for stability class $A$, whereas the highest values are used under very stable situations, $\alpha=0.30$ for stability class F. Moreover, when roughness increases such as at urban areas, $\alpha$ may be higher than 0.40 [39]. Since wind speed was recorded at $2 \mathrm{~m}$ in 20 stations, Eq. (3) was used to analyse wind speed at $10 \mathrm{~m}$ in all the stations at an initial 
stage and at $50 \mathrm{~m}$ at a second stage in order to perform wind density power calculations.

\subsection{The Weibull probability density function}

This is a two-parameter distribution function [40], which is typically used in wind speed analyses. Noticeable recent applications include the wind study using LiDAR technology at a site around Lake Erie [41], the description of wind resources in Northern Ethiopia for water pumping and electricity generation [42], and determining optimal placements of wind farms in Turkey [43]. Its mathematical expression is

$f(v)=\left(\frac{k}{c}\right)\left(\frac{v}{c}\right)^{k-1} e^{-\left(\frac{v}{c}\right)^{k}}$,

where $k$ and $c$ are the shape and scale parameters, respectively. In Eq. (4), both the wind speed and the scale parameter should be positive [44]. When the probability of null wind is significant, the three-parameter Weibull distribution is employed [45].

\subsection{The method of moments}

Different procedures have been suggested to calculate the shape and scale parameters $[46,47]$. One of the simplest is the method of moments, which needs the mean speed $\bar{v}$ and the standard deviation of wind speed, $\sigma$,

$\bar{v}=\frac{\sum_{i=1}^{n} v_{i}}{n}$

$\sigma=\sqrt{\frac{\sum_{i=1}^{n}\left(v_{i}-\bar{v}\right)^{2}}{n-1}}$,

where $n$ is the number of observations $v_{i}$. Values of Eqs. (5) and (6) are used to calculate the Weibull shape parameter using the expression proposed by Justus et al. [48],

$k=\left(\frac{\sigma}{\bar{v}}\right)^{-1.086} \quad(1 \leq k \leq 10)$

With the value of $k$ proposed by Eq. (7), the scale parameter, $c$, may easily be obtained by one of the following expressions

$\bar{v}=c \Gamma\left[1+\frac{1}{k}\right]$,

$\sigma=c\left[\Gamma\left(1+\frac{2}{k}\right)-\Gamma^{2}\left(1+\frac{1}{k}\right)\right]^{1 / 2}$

where $T$ is the gamma function. Eq. (8) was considered in this paper due to its greater simplicity when compared to Eq. (9). The main advantage of this procedure is its simplicity, since the Weibull parameters are obtained directly. Although the maximum-likelihood method is frequently used, its iterative solution makes it more complex. Moreover, large datasets may slow down the calculation. Another simple procedure is the cumulative probability method, where the Weibull parameters are obtained by linear regression [49], although outliers might impact on the result.

\subsection{Wind power density}

Once the Weibull parameters are calculated, the wind power density, $W P D$, is obtained with
$W P D=\frac{1}{2} \rho c^{3} \Gamma\left[1+\frac{3}{k}\right]$

where $\rho$ is the air density. The scale parameter shows how "windy" a site is. When it doubles, Eq. (10) indicates that WPD increases eight fold. The shape parameter is related with the shape of the wind distribution. A maximum away from the origin is observed when $k>1$. The Rayleigh distribution is obtained for $k=2$, and an approximation to the Gaussian distribution is associated with $k=3.6$. Moreover, $k$ close to 1 indicates highly variable winds, whereas $k \geq 3$ corresponds to more regular winds. When the shape parameter increases from 1.5 to 3 , the distribution function is more symmetric, the wind is more regular and WPD decreases by half.

Although a typical value of $1.225 \mathrm{~kg} \mathrm{~m}^{-3}$ has sometimes been used for air density [50], in this study it was calculated by

$\rho=\frac{p}{R \mathrm{~T}}$

In Eq. (11), $R$ is the universal gas constant, $288.11 \mathrm{~m}^{3} \mathrm{~Pa} \mathrm{~kg}{ }^{-1} \cdot \mathrm{K}^{-1}$, and $T$ and $p$ are temperature and air pressure, which depend on height by the expression

$p=p_{r}\left(\frac{T_{r}-\gamma h}{T_{r}}\right)^{\left(\frac{g}{R \gamma}\right)}$,

where $g$ is gravity at the Earth's surface, $\gamma$ the environmental lapse rate, $6.5 \mathrm{~K} \mathrm{~km}^{-1}, T_{r}$ the sea level temperature and $p_{r}$ the pressure at sea level, taken as $1013.25 \mathrm{hPa}$. This procedure has been followed by Kruyt et al. [51].

\subsection{Image analysis}

Contour lines were traced to obtain a spatial representation of the variables calculated. Since these graphs are pixelated, pixels between consecutive lines may be counted to estimate the corresponding surface area.

\section{Results}

Fig. 2 presents the wind speed observations at stations located in the three differentiated areas of the region presented in Section 2.1. Trinidad de Iturgoien, Fig. 2(a), shows a noticeable median wind speed, $6.8 \mathrm{~m} \mathrm{~s}^{-1}$, and the skewness is also marked by the isolated observations above $15 \mathrm{~m} \mathrm{~s}^{-1}$, which are mainly in winter and may be explained by the low pressure systems that sweep the Iberian Peninsula in this season. Carrascal, Fig. 2(b), presents a few observations above $15 \mathrm{~m} \mathrm{~s}^{-1}$ and no seasonal pattern may be seen when observing the high wind speeds. However, said pattern does appear at low wind speeds, since certain observations are smaller in winter than in summer. This behaviour might be attributed to the orography of the region, which determines thermally induced winds. Finally, a low median wind speed, $3.7 \mathrm{~m} \mathrm{~s}^{-1}$, is observed in Tudela, Fig. 2(c), where only a few observations are above $10 \mathrm{~m} \mathrm{~s}^{-1}$ and the seasonal pattern of the low values is similar to that observed in Carrascal.

\subsection{Statistics}

Table 1 presents the mean values for 2,10 and $50 \mathrm{~m}$ height. One noticeable feature is the increasing dependence with height for the mean, median, standard deviation and interquartile range. Moreover, as the robust skewness, Eq. (1), is limited, it displays a lower range $(0.281$ at $10 \mathrm{~m})$ than the skewness $(1.809)$, which is more 


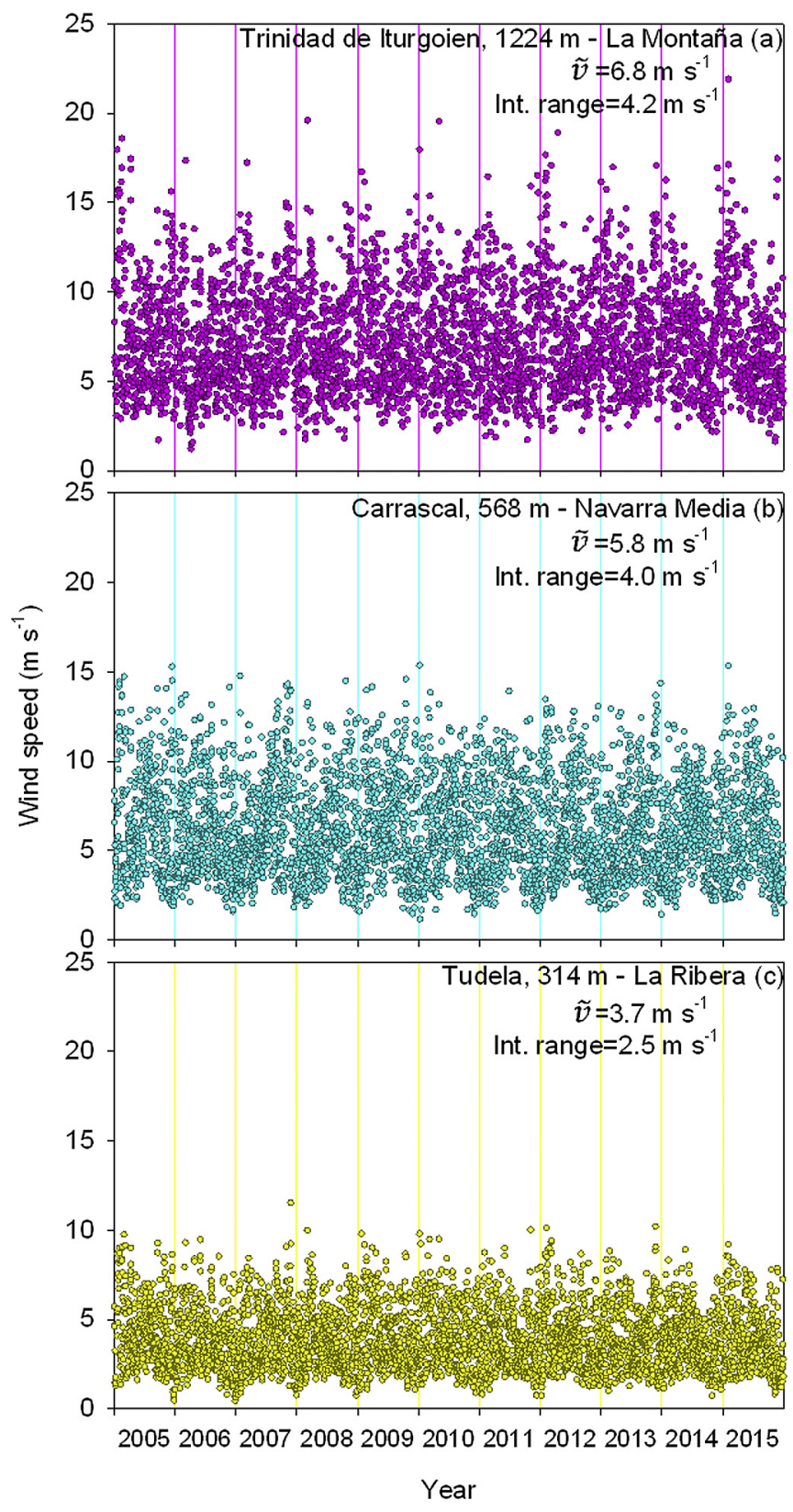

Fig. 2. Observations recorded in the period 2005-2015 together with their median and interquartile range at Trinidad de Iturgoien, in the highest area of the region, "La Montaña" (a), Carrascal, in the middle-height part, "Navarra Media" (b), and Tudela, in the lowest area, "La Ribera" (c).

Table 1

Mean values of different statistics for wind speed recorded at the weather stations considered in this study.

\begin{tabular}{llll}
\hline Statistic & \multicolumn{2}{l}{ Height $(\mathrm{m})$} & \\
\cline { 2 - 4 } & 2 & 10 & 50 \\
\hline Mean $\left(\mathrm{m} \mathrm{s}^{-1}\right)$ & 2.80 & 3.59 & 4.43 \\
Median $\left(\mathrm{m} \mathrm{s}^{-1}\right)$ & 2.58 & 3.28 & 4.08 \\
Standard deviation $\left(\mathrm{m} \mathrm{s}^{-1}\right)$ & 1.41 & 1.74 & 2.28 \\
Interquartile range $\left(\mathrm{m} \mathrm{s}^{-1}\right)$ & 1.86 & 2.33 & 2.99 \\
Skewness & 0.81 & 0.90 & 0.76 \\
Robust skewness & 0.14 & 0.14 & 0.14 \\
Kurtosis & 1.03 & 1.14 & 1.00 \\
Robust kurtosis & 0.26 & 0.27 & 0.26 \\
\hline
\end{tabular}

sensitive to outliers, with both remaining positive, since distributions are right skewed. A consequence of this distribution shape is that the mean wind speed is above its corresponding median. A similar response is observed for the robust kurtosis, Eq. (2), whose range (1.587 at $10 \mathrm{~m})$ is smaller than that of the kurtosis (7.498).

Analysis of skewness and kurtosis is not common. However, Torres et al. studied both statistics with 11 meteorological stations in the same region over four years [52]. They considered two groups of stations; those under the influence of the Ebro river valley and stations under mountain influence. Eight directional sectors were used and the fraction of the time in which the wind blew in each sector was calculated. Different values were obtained for the two parameters. Although a decreasing trend was marked, these statistics fell when the time fraction increased, i.e. when the wind direction moved to the most frequent direction.

Shoaib et al. analysed wind speed features at Baburband (Pakistan) at 81.5, 80, 60 and $30 \mathrm{~m}$ during five periods [53]. Mean values at the lowest levels were higher than obtained in this study at $50 \mathrm{~m}$, although the standard deviation is comparable in one of the periods presented. Skewness is mainly positive, although two small negative values are obtained at 81.5 and $80 \mathrm{~m}$, revealing nearly symmetrical or slightly left skewed distributions. Kurtosis is close to zero, negative in four periods and positive in the remaining one. Kantar et al. also presented descriptive statistics for wind speed observations measured at $10 \mathrm{~m}$ at three sites in Turkey [54]. Mean and skewness are comparable to values in Table 1 for only one site, with the remaining ones being higher.

Fig. 3 presents the spatial distribution of these robust statistics at $10 \mathrm{~m}$. Analysis of this figure is based on the scales presented and is shown by two values, one for about half of the surface and the second for a low percentile linked with a high value of the variable studied. Fig. 3(a) reveals that around $49 \%$ of the surface area corresponds to wind speed medians above $3 \mathrm{~m} \mathrm{~s}^{-1}$, which is a low value, and $9 \%$ above $5 \mathrm{~m} \mathrm{~s}^{-1}$. Nedaei et al. presented a similar representation for mean wind speed at $40 \mathrm{~m}$ from 68 sites in Iran in order to select which regions displayed the greatest potential for wind turbine development [55]. The interquartile range, Fig. 3(b), is above $2 \mathrm{~m} \mathrm{~s}^{-1}$ for about $57 \%$ of the area, similar to the wind speed median, and above $3.2 \mathrm{~m} \mathrm{~s}^{-1}$ for $12 \%$. Surface is around $60 \%$ of the region for a robust skewness above 0.13 and around $8 \%$ for a value above 0.21, Fig. 3(c). Finally, the robust kurtosis, Fig. 3(d), is above 0.26 for about $55 \%$ of the region and above 0.28 for $5 \%$.

Comparing Fig. 3 with Fig. 1(b) reveals a noticeable relationship with height for the median and interquartile range. The absence of stations to the northeast determines the lack of agreement with the relief in this area. However, that relationship is less pronounced for the robust skewness and kurtosis, where the most marked values are observed in the centre of the region.

Table 2 quantifies the correlation with height for the statistics calculated. One noticeable result is that mean wind speed at $10 \mathrm{~m}$ a.g.l. increases at a rate of nearly $0.5 \mathrm{~m} \mathrm{~s}^{-1}$ when ground surface increases $100 \mathrm{~m}$ in height. Correlation with height may not be concluded for the skewness and kurtosis due to the low values of the correlation coefficient. For these variables, their values are provided by the intercept of the linear equation, with the slope determining a slight change.

\subsection{The Weibull distribution parameters}

Table 3 presents the mean values for all the weather stations used at 2,10 and $50 \mathrm{~m}$. The $k$ values are around 2, corresponding to moderately gusty winds, and the $c$ parameter, which is proportional to the mean wind speed, increases with height.

Both parameters, corresponding to $10 \mathrm{~m}$ height, are plotted in Fig. 4 and their correlation with height in Fig. 5. The $k$ range is 

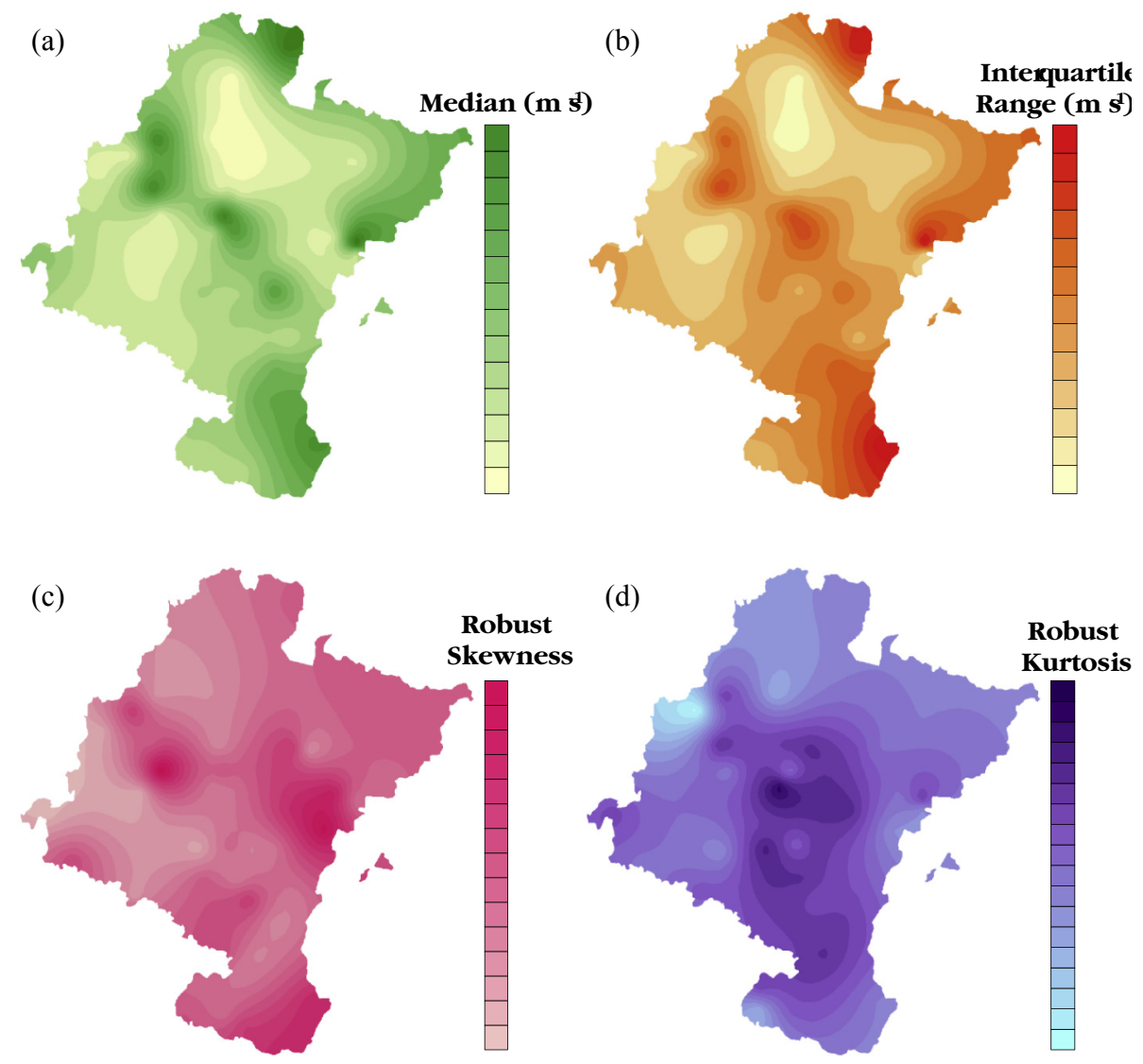

Fig. 3. Maps of the median (a), interquartile range (b), robust skewness (c) and robust kurtosis (d) of wind speed at $10 \mathrm{~m}$.

Table 2

Linear regressions $y=a h+b$, where $y$ is the corresponding statistic, $h(\mathrm{~m})$ the height of the station, and $r$ the correlation coefficient.

\begin{tabular}{llll}
\hline Statistic & $a$ & $b$ & $r$ \\
\hline Mean $\left(\mathrm{m} \mathrm{s}^{-1}\right)$ & $4.510^{-3}$ & 1.134 & $0.692^{\mathrm{c}}$ \\
Median $\left(\mathrm{m} \mathrm{s}^{-1}\right)$ & $4.310^{-3}$ & 0.957 & $0.701^{\mathrm{c}}$ \\
Standard deviation $\left(\mathrm{m} \mathrm{s}^{-1}\right)$ & $1.410^{-3}$ & 0.951 & $0.537^{\mathrm{c}}$ \\
Interquartile range $\left(\mathrm{m} \mathrm{s}^{-1}\right)$ & $2.010^{-3}$ & 1.261 & $0.508^{\mathrm{c}}$ \\
Skewness & $3.010^{-5}$ & 0.884 & 0.022 \\
Robust skewness & $-3.010^{-6}$ & 0.145 & 0.014 \\
Kurtosis & $1.010^{-6}$ & 1.144 & 0.000 \\
Robust kurtosis & $-1.010^{-6}$ & 0.267 & 0.024
\end{tabular}

${ }^{\mathrm{c}}$ These correlations are statistically significant at a 95\% significance level.

Table 3

Mean values of the parameters for the weather stations considered.

\begin{tabular}{llll}
\hline Parameter & \multicolumn{2}{l}{ Height $(\mathrm{m})$} & 50 \\
\cline { 2 - 4 } & 2 & 10 & 2.07 \\
\hline $\mathrm{k}$ & 2.12 & 2.20 & 4.98 \\
\hline
\end{tabular}

narrow, 1.67 at $10 \mathrm{~m}$, and the surface is around $51 \%$ for $k$ above 2.25 , and for $6 \%$ of the region is above 2.7 . Its correlation with height is satisfactory since $r$ is equal to 0.473 , which is higher than the critical value of 0.291 for a $95 \%$ confidence level. The highest values, around 3 , are near the north of the region, indicating a probability density function with noticeable symmetry, close to the Gaussian one, whereas the lowest values, near 1.5, appear close to the south and are linked to skewed distributions. The $c$ range is $8.20 \mathrm{~m} \mathrm{~s}^{-1}$ at $10 \mathrm{~m}$, and around $41 \%$ of the region shows values above $4 \mathrm{~m} \mathrm{~s}^{-1}$. These values exceed $7 \mathrm{~m} \mathrm{~s}^{-1}$ for about $4 \%$ of the area. Fig. 4(b) is similar to Fig. 1(b) showing the close relationship between the scale parameter and the relief. Consequently, correlation with height is better for the $c$ parameter $(r=0.691)$ than for $k$. This result reveals that the shapes of the probability density functions are similar in most of the region, whose $k$ are contained in a narrow interval, whereas the scale parameter, linked to wind speed, increases when height also grows.

Jovic et al. calculated both parameters for different heights at the city of Nin in Serbia [56]. A similar value to that appearing in Table 3 for $c$ at $10 \mathrm{~m}$ emerged, although $k$ was around 1.7, revealing a skewed distribution. Benmemdejahed and Mouhadjer considered five sites in the Algerian Sahara, where $k$ values at $10 \mathrm{~m}$ lay between 2 and 2.5, and where $c$ was around or above $6 \mathrm{~m} \mathrm{~s}^{-1}$ [57]. Most of the shape parameters calculated by Soltani and Fazelpour in the city of Kahnuj in Iran for that height were above 2 , whereas the scale parameters were mainly below $8 \mathrm{~m} \mathrm{~s}^{-1}$ [58]. Sarkar et al. analysed hourly wind speed at $10 \mathrm{~m}$ for 40 stations in India and obtained $k$ values between 1.3 and 2.3 , and $c$ values from 1.4 to $6.5 \mathrm{~m} \mathrm{~s}^{-1}$ [59], in agreement with the values calculated in this study. Allouhi et al. considered six coastal sites in Morocco and reported values of both parameters for wind speeds at $50 \mathrm{~m}$ where $k$ was in the 2.0-4.4 range [60]. However, $c$ values were above $8 \mathrm{~m} \mathrm{~s}^{-1}$ at two sites. The lower $c$ observed in Navarre is due to the large number of sites used whose wind speeds are mainly low. 


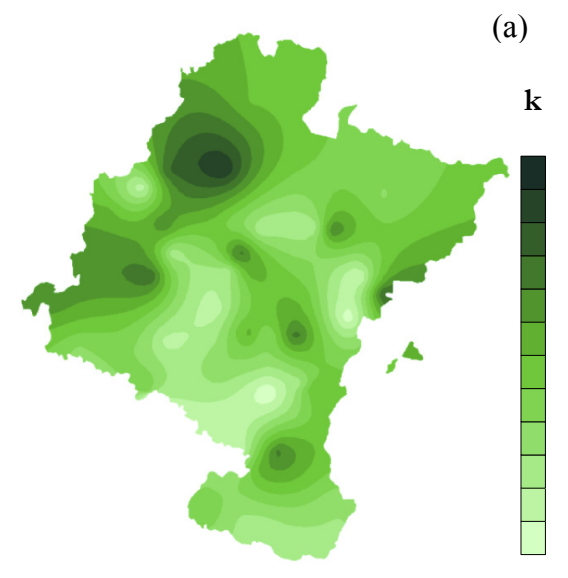

(a)

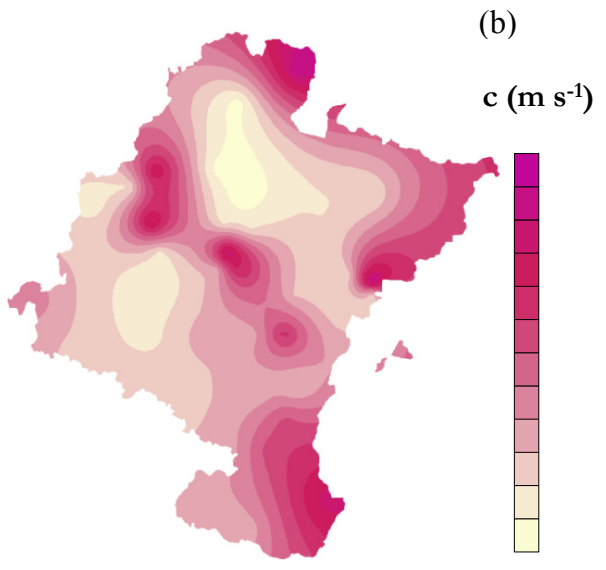

Fig. 4. Maps of $k$ (a) and $c$ (b) parameters for wind speeds at $10 \mathrm{~m}$.

(a)

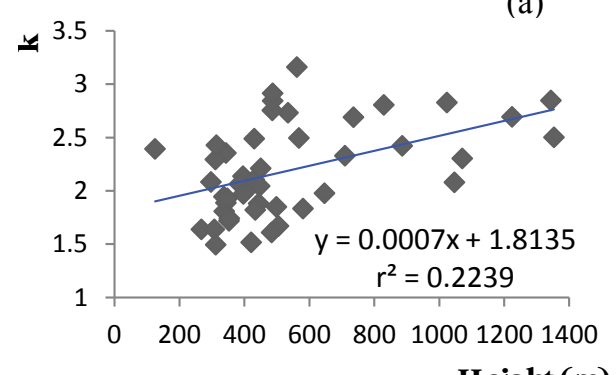

(b)

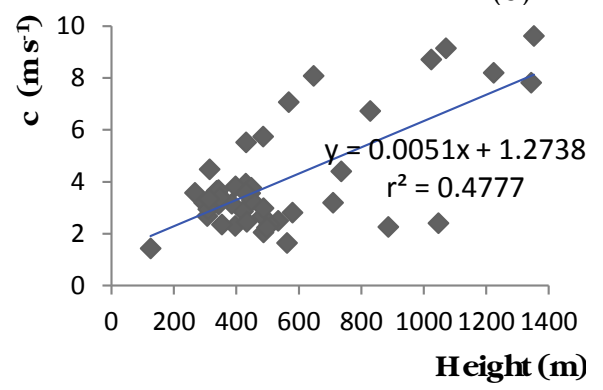

Fig. 5. Correlation graphics of $k(\mathrm{a})$ and $c(\mathrm{~b})$ with height.

\subsection{Wind power density}

Although the trend towards taller towers is evidently determined by larger rotor diameters [61], a low hub height of $50 \mathrm{~m}$ corresponding to midsize and community-scale wind projects was used in this paper. This height is uncommon in North America and rare in Europe, although it is slightly more common in Asia and the rest of the world [62]. Premono et al. presented turbines with hub height from 30.5 to $75 \mathrm{~m}$ in their analysis of wind energy potential assessment on the northern coast of central Java, Indonesia [63], and Vasel-Be-Hagh and Archer calculated 5.4\% more power when rows of tall $(100 \mathrm{~m})$ and short $(57.5 \mathrm{~m})$ wind turbines are alternated [64].

Table 4 presents the average air density calculated with Eqs. (11) and (12) for all the stations obtained for three $T_{r}, 283,288$ and $293 \mathrm{~K}$, which are suitable for the region and which were chosen to investigate their influence on the average wind power density. Baseer et al. calculated $1.17 \mathrm{~kg} \mathrm{~m}^{-3}$ as the overall mean air density at one station in their study of wind power characteristics in Jubail, Saudi Arabia [65]. A look at Table 4 shows that an increase of five degrees in temperature leads to a reduction of around $1.7 \%$ for air density and $1.6 \%$ for WPD.

\section{Table 4}

Average air density and wind power density at $50 \mathrm{~m}$ height for three temperatures at sea level.

\begin{tabular}{lll}
\hline $\mathrm{T}(\mathrm{K})$ & Air density $\left(\mathrm{kg} \mathrm{m}^{-3}\right)$ & $\mathrm{WPD}\left(\mathrm{W} \mathrm{m}^{-2}\right)$ \\
\hline 283 & 1.17 & 171.39 \\
288 & 1.15 & 168.68 \\
293 & 1.13 & 166.05 \\
\hline
\end{tabular}

The spatial distribution of the power density for $288 \mathrm{~K}$ is shown in Fig. 6, and displays a noticeable contrast between the highest values, close to $1000 \mathrm{~W} \mathrm{~m}^{-2}$, obtained at high altitudes, and the smallest, mainly obtained at the stations with the lowest altitudes, especially those located in valleys between mountains. Wide areas in the centre north and south of the region with extremely low

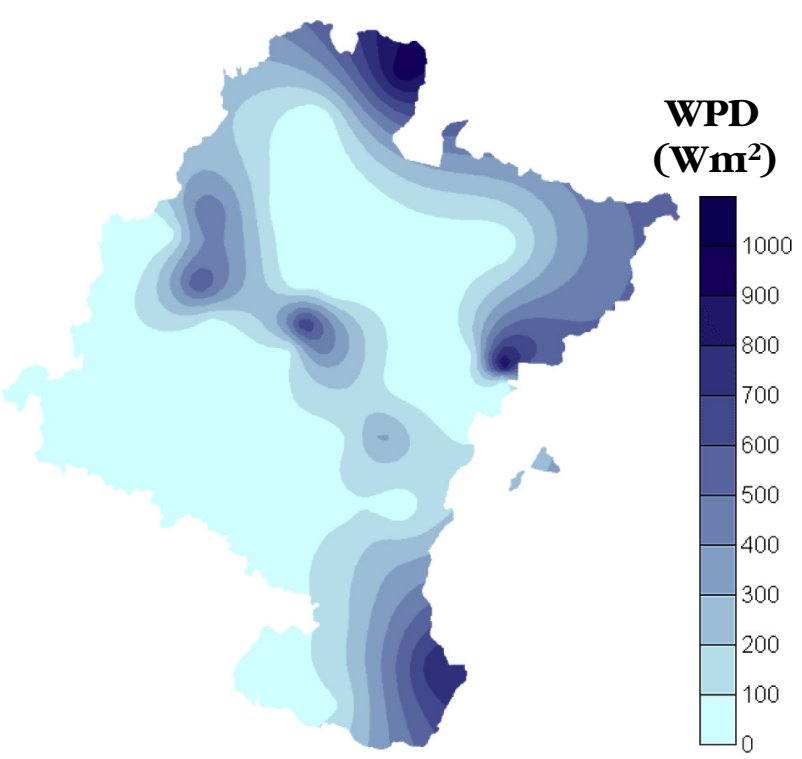

Fig. 6. Map of $W P D$ at $50 \mathrm{~m}$ height. 


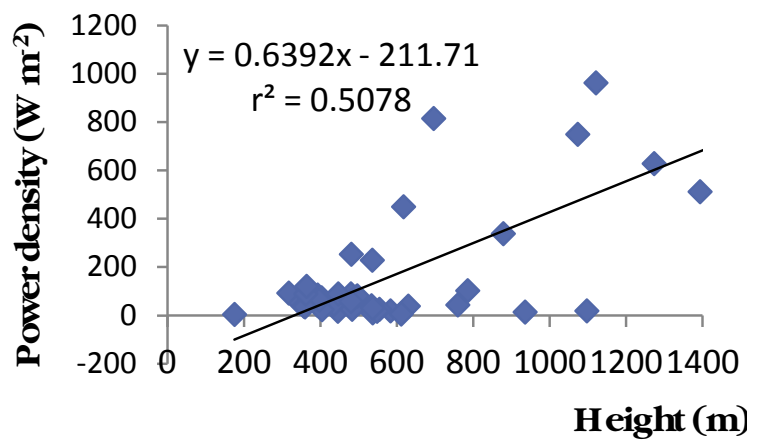

Fig. 7. Correlation of $W P D$ at $50 \mathrm{~m}$ with height.

values of WPD are a noticeable feature. The linear relationship between wind power density and height shown in Fig. 7 proves satisfactory since the correlation coefficient is 0.713 . However, this quantity is marked by the four stations with large values of both height and WPD.

Akpinar and Akpinar presented the seasonal evolution of wind speed at four sites in Turkey and calculated the wind speed profiles and WPD for the highest seasonal wind speed [66]. The WPD range at $50 \mathrm{~m}$ was between around $400 \mathrm{~W} \mathrm{~m}^{-2}$ and nearly $25 \mathrm{~W} \mathrm{~m}^{-2}$. Silva dos Santos et al. estimated WPD above $400 \mathrm{~W} \mathrm{~m}^{-2}$ at 60 and $50 \mathrm{~m}$ height at two locations in Brazil [67]. WPD at $50 \mathrm{~m}$ between around 61 and $125 \mathrm{~W} \mathrm{~m}^{-2}$ were calculated by Islam et al. in Bangladesh [68].

The WPD classification [60,69] and surface calculations presented in Table 5 reveal that most of the region $(64.1 \%)$ is not suitable for wind turbine applications, in agreement with Fig. 6 . However, $12.5 \%$ of the area is suitable for stand-alone applications, and $23.4 \%$ of the surface presents adequate wind resources for wind turbine applications.

Similarly, Li et al. analysed two sites in China following Table 5 and concluded that the first, Urumqi, was not suitable for largescale electric wind-power application, although wind-hybrid power systems or small scale wind turbines may be implemented for lighting, chargers or electric fans [70]. The other site, Xining, was suitable for medium scale wind turbines.

\section{Conclusions}

Analysis of daily wind speed recorded from 2005 to 2015 at 46 weather stations in the region of Navarre, northern Spain, revealed low wind speed values, with a median of about $3.3 \mathrm{~m} \mathrm{~s}^{-1}$ at $10 \mathrm{~m}$ and a narrow interquartile range of about $2.3 \mathrm{~m} \mathrm{~s}^{-1}$. Observations were slightly right skewed, with a robust skewness of 0.14 , and were similarly peaked to the Gaussian distribution, since the robust

Table 5

Wind power density classification for wind speed at $50 \mathrm{~m}$ and surface fraction of the region for each class.

\begin{tabular}{llll}
\hline $\begin{array}{l}\text { Wind power } \\
\text { class }\end{array}$ & WPD $\left(\mathrm{W} \mathrm{m}^{-2}\right)$ & $\begin{array}{l}\text { Resource } \\
\text { potential }\end{array}$ & $\begin{array}{l}\text { Fraction of } \\
\text { surface (\%) }\end{array}$ \\
\hline 1 & $0-200$ & $\begin{array}{l}\text { Not suitable } \\
\text { Suitable for } \\
\text { stand-alone }\end{array}$ & 64.1 \\
2 & $200-300$ & $\begin{array}{l}\text { applications } \\
\text { Good }\end{array}$ & \\
& & Good & 8.4 \\
3 & $300-400$ & Excellent & 7.3 \\
4 & $400-500$ & Outstanding & 3.9 \\
5 & $500-600$ & Superb & 2.8 \\
6 & $600-800$ & & 1.0 \\
7
\end{tabular}

kurtosis was 0.27. Image analysis showed the spatial extension of the variables measured. Wind speed median at $10 \mathrm{~m}$ was above $5 \mathrm{~m} \mathrm{~s}^{-1}$ in around $9 \%$ of the region and the interquartile range was $3.2 \mathrm{~m} \mathrm{~s}^{-1}$ on nearly $11 \%$ of the surface. The median and interquartile ranges evidenced a noticeable link with height, with correlation coefficients above 0.5 , this relationship not proving significant for robust skewness and kurtosis. The Weibull distribution parameters were calculated, with the scale parameter being low, $4.04 \mathrm{~m} \mathrm{~s}^{-1}$ at $10 \mathrm{~m}$, since it is proportional to wind speed. This parameter was above $4 \mathrm{~m} \mathrm{~s}^{-1}$ in around $41 \%$ of the region. The shape parameter, with a mean of 2.20 at $10 \mathrm{~m}$, corresponded to moderately gusty winds and was above 2.25 on more than half of the surface. The relationship of the two parameters with the height of the stations was satisfactory, especially for the scale parameter, $r=0.691$. Wind power density at $50 \mathrm{~m}$ was obtained from the Weibull parameters by considering the change of air density with height. Spatial analysis indicated that around $23 \%$ of the surface is suitable for wind turbine applications. Finally, this study expands typical wind speed analysis with surface area estimation, and correlation with height, which have proved useful tools to determine locations suitable for installing wind power generators.

\section{Conflict of interests}

The authors declare that there is no conflict of interests regarding publication of this paper.

\section{Acknowledgements}

The authors wish to acknowledge the financial support of the Ministry of Economy and Competitiveness and ERDF funds (project numbers CGL2009-11979 and CGL2014-53948-P).

\section{References}

[1] Razavieh A, Sedaghat A, Ayodele R, Mostafaeipour A. Worldwide wind energy status and the characteristics of wind energy in Iran, case study: the province of Sistan and Baluchestan. Int J Sustain Energy 2017;36:103-23. http:// dx.doi.org/10.1080/14786451.2014.977288.

[2] El sistema eléctrico español 2016. 2017 [Accessed 14 June 2017], http://www. ree.es/es.

[3] EWEA. Wind energy scenarios for 2030. The European Wind Energy Association; 2015 [Accessed 14 June 2017], https://windeurope.org/about-wind/ reports/wind-energy-scenarios-2030/.

[4] Ouammi A, Dagdougui H, Sacile R, Mimet A. Monthly and seasonal assessment of wind energy characteristics at four monitored locations in Liguria region (Italy). Renew Sust Energ Rev 2010;14:1959-68. http://dx.doi.org/10.1016/ j.rser.2010.04.015.

[5] Rehman S, Ahmad A. Assessment of wind energy potential for coastal locations of the Kingdom of Saudi Arabia. Energy 2004;29:1105-15. http:// dx.doi.org/10.1016/j.energy.2004.02.026.

[6] Giannaros TM, Melas D, Ziomas I. Performance evaluation of the Weather Research and Forecasting (WRF) model for assessing wind resource in Greece. Renew Energy 2017;102:190-8. http://dx.doi.org/10.1016/ j.renene.2016.10.033.

[7] Santos-Alamillos FJ, Thomaidis NS, Quesada-Ruiz S, Ruiz-Arias JA, PozoVázquez D. Do current wind farms in Spain take maximum advantage of spatiotemporal balancing of the wind resource? Renew Energy 2016;96: 574-82. http://dx.doi.org/10.1016/j.renene.2016.05.019.

[8] Lawan SM, Abidin WAWZ, Masri T, Chai WY, Baharun A. Wind power generation via ground wind station and topographical feedforward neural network (T-FFNN) model for small-scale applications. J Clean Prod 2017;143: 1246-59. http://dx.doi.org/10.1016/j.jclepro.2016.11.157.

[9] Hdidouan D, Staffell I. The impact of climate change on the levelised cost of wind energy. Renew Energy 2017;101:575-92. http://dx.doi.org/10.1016/ j.renene.2016.09.003.

[10] Ganea D, Amortila V, Mereuta E, Rusu E. A joint evaluation of the wind and wave energy resources close to the Greek Islands. Sustainability 2017;9, 1025. http://dx.doi.org/10.3390/su9061025.

[11] Kutucu H, Almryad A. An application of artificial neural networks to assessment of the wind energy potential in Libya. In: 7th international conference on sciences of electronics, technologies of information and telecommunications (SETIT 2016) 2017; 2016. p. 405-9, 7939904. http://dx.doi.org/10.1109/ SETIT.2016.7939904. 
[12] Fernandez-Bernal F, Alonso-Alonso J. Wind speed generation for dynamic analysis. Wind Energy 2017;20:1049-68. http://dx.doi.org/10.1002/we.2079.

[13] Mohammadpour Penchah M, Malakooti H, Satkin M. Evaluation of planetary boundary layer simulations for wind resource study in east of Iran. Renew Energy 2017;111:1-10. http://dx.doi.org/10.1016/j.renene.2017.03.040.

[14] Alavi O, Mohammadi K, Mostafaeipour A. Evaluating the suitability of wind speed probability distribution models: a case of study of east and southeast parts of Iran. Energy Conv Manag 2016;119:101-8. http://dx.doi.org/10.1016/ j.enconman.2016.04.039.

[15] Ouarda TBMJ, Charron C, Chebana F. Review of criteria for the selection of probability distributions for wind speed data and introduction of the moment and L-moment ratio diagram methods, with a case study. Energy Conv Manag 2016:124:247-65. http://dx.doi.org/10.1016/j.enconman.2016.07.012.

[16] Akgül FG, Şenoğlu B, Arslan T. An alternative distribution to Weibull for modeling the wind speed data: inverse Weibull distribution. Energy Conv Manag 2016;114:234-40. http://dx.doi.org/10.1016/j.enconman.2016.02.026.

[17] Alavi O, Sedaghat A, Mostafaeipour A. Sensitivity analysis of different wind speed distribution models with actual and truncated wind data: a case study for Kerman. Iran Energy Conv Manag 2016;120:51-61. http://dx.doi.org/ 10.1016/j.enconman.2016.04.078.

[18] Saboor A, Bakouch HS, Nauman Khan M. Beta Sarhan-Zaindin modified Weibull distribution. Appl Math Model 2016;40:6604-21. http://dx.doi.org/ 10.1016/j.apm.2016.01.033.

[19] Mohammadi K, Alavi O, McGowan JG. Use of Birnbaum-Saunders distribution for estimating wind speed and wind power probability distributions: a re view. Energy Conv Manag 2017;143:109-22. http://dx.doi.org/10.1016 j.enconman.2017.03.083.

[20] Jung C, Schindler D. Global comparison of the goodness-of-fit of wind speed distributions. Energy Conv Manag 2017;133:216-34. http://dx.doi.org 10.1016/j.enconman.2016.12.006.

[21] Pérez IA, García MA, Sánchez ML, de Torre B. Description of atmospheric variables measured with a RASS sodar: cycles and distribution functions J Wind Eng Ind Aerodyn 2008;96:436-53. http://dx.doi.org/10.1016/ j.jweia.2008.01.001.

[22] Yürüşen NY, Melero JJ. Probability density function selection based on the characteristics of wind speed data. J Phys Conf Ser 2016;753, 032067. http:// dx.doi.org/10.1088/1742-6596/753/3/032067.

[23] Solyali D, Altunç M, Tolun S, Aslan Z. Wind resource assessment of Northern Cyprus. Renew Sust Energ Rev 2016;55:180-7. http://dx.doi.org/10.1016/ j.rser.2015.10.123.

[24] Lee JK, Lee KH, Kim SI, Yook D, Ahn S. Weibull parameter calculation and estimation of wind speeds for the return period: a case study in the Kori and Wolsong NPP areas. Ann Nucl Energy 2017;108:406-12. http://dx.doi.org/ 10.1016/j.anucene.2017.04.040.

[25] Altmimi A, Ceekhan A. Calculate and compare five of Weibull distribution parameters to estimate wind power in Iraq. In: 8th international renewable energy congress (IREC 2017) 2017; 2017, 7926044. http://dx.doi.org/10.1109/ IREC.2017.7926044.

[26] Ban M, Perković L, Duić N, Penedo R. Estimating the spatial distribution of high altitude wind energy potential in Southeast Europe. Energy 2013;57: 24-9. http://dx.doi.org/10.1016/j.energy.2012.12.045.

[27] Usta I, Kantar YM, Arik I, Yenilmez I. A statistical investigation on wind energy potential of Northwest of Turkey. In: Proceedings - 2016 international conference on engineering and MIS. ICEMIS; 2016, 7745315. http://dx.doi.org/ 10.1109/ICEMIS.2016.7745315.

[28] Albadi MH, El-Saadany EF. Optimum turbine-site matching. Energy 2010;35: 3593-602. http://dx.doi.org/10.1016/j.energy.2010.04.049.

[29] Weekes SM, Tomlin AS. Data efficient measure-correlate-predict approaches to wind resource assessment for small-scale wind energy. Renew Energy 2014;63:162-71. http://dx.doi.org/10.1016/j.renene.2013.08.033.

[30] Helbig N, Mott R, van Herwijnen A, Winstral A, Jonas T. Parameterizing surface wind speed over complex topography. J Geophys Res Atmos 2017;122: 651-67. http://dx.doi.org/10.1002/2016JD025593.

[31] Siyal SH, Mörtberg U, Mentis D, Welsch M, Babelon I, Howells M. Wind energy assessment considering geographic and environmental restrictions in Sweden: a GIS-based approach. Energy 2015;83:447-61. http://dx.doi.org/ 10.1016/j.energy.2015.02.044.

[32] Gobierno de Navarra. Meteorología y climatología de Navarra. 2016. http:/| meteo.navarra.es/estaciones/descargardatos.cfm [Accessed 14 June 2017].

[33] Bonato M. Robust estimation of skewness and kurtosis in distributions with infinite higher moments. Financ Res Lett 2011;8:77-87. http://dx.doi.org/ 10.1016/j.frl.2010.12.001.

[34] Ekström M, Jammalamadaka SR. A general measure of skewness. Stat Probab Lett 2012;82:1559-68. http://dx.doi.org/10.1016/j.spl.2012.04.011.

[35] Wilks DS. Statistical methods in the atmospheric sciences. 3th ed. Oxford: Academic Press; 2011.

[36] Sachs L. Applied statistics. A handbook of techniques. New York: SpringerVerlag; 1982.

[37] Pérez IA, García MA, Sánchez ML, de Torre B. Analysis and parameterisation of wind profiles in the low atmosphere. Sol Energy 2005;78:809-21. http:// dx.doi.org/10.1016/j.solener.2004.08.024.

[38] Pérez IA, Sánchez ML, García MA, de Torre B. Description and distribution fitting of transformed sodar wind observations. J Atmos Sol Terr Phys 2008;70:89-100. http://dx.doi.org/10.1016/j.jastp.2007.10.004.

[39] Beychok MR. Fundamentals of stack gas dispersion. Irvine, CA: Milton R.
Beychok; 1994.

[40] Weibull W. A statistical distribution function of wide applicability. J Appl Mech 1951;18:293-7.

[41] Li J, Yu XB. LiDAR technology for wind energy potential assessment: demonstration and validation at a site around Lake Erie. Energy Conv Manag 2017;144:252-61. http://dx.doi.org/10.1016/j.enconman.2017.04.061.

[42] Kodicherla SPK, Gaddada S, Shaik N. Wind energy potential and economic evaluation of WPS using WECSs in three selected locations of Northern Ethiopia. Afr J Sci Technol Innov Dev 2017;9:179-87. http://dx.doi.org/ 10.1080/20421338.2017.1303990.

[43] Cetinay H, Kuipers FA, Guven AN. Optimal siting and sizing of wind farms. Renew Energy 2017;101:51-8. http://dx.doi.org/10.1016/j.renene. 2016.08.008.

[44] Wais P. Two and three-parameter Weibull distribution in available wind power analysis. Renew Energy 2017;103:15-29. http://dx.doi.org/10.1016/ j.renene.2016.10.041.

[45] Wais P. A review of Weibull functions in wind sector. Renew Sust Energ Rev 2017;70:1099-107. http://dx.doi.org/10.1016/j.rser.2016.12.014.

[46] Pérez IA, García MA, Sánchez ML, de Torre B. Analysis of height variations of sodar-derived wind speeds in Northern Spain. J Wind Eng Ind Aerodyn 2004;92:875-94. http://dx.doi.org/10.1016/j.jweia.2004.05.002.

[47] Pérez IA, Sánchez ML, García MA. Weibull wind speed distribution: numerical considerations and use with sodar data. J Geophys Res 2007;112:D20112. http://dx.doi.org/10.1029/2006JD008278.

[48] Justus CG, Hargraves WR, Mikhail A, Graber D. Methods for estimating wind speed frequency distributions. J Appl Meteorol 1978;17:350-3.

[49] Fetisova YA, Ermolenko BV, Ermolenko GV, Kiseleva SV. Determining the parameters of Weibull function to estimate the wind power potential in conditions of limited source meteorological data. Therm Eng 2017;64:251-7. http://dx.doi.org/10.1134/S0040601517040036.

[50] Carrasco-Díaz M, Rivas D, Orozco-Contreras M, Sánchez-Montante O. An assessment of wind power potential along the coast of Tamaulipas, northeastern Mexico. Renew Energy 2015;78:295-305. http://dx.doi.org/10.1016/ j.renene.2015.01.007.

[51] Kruyt B, Lehning M, Kahl A. Potential contributions of wind power to a stable and highly renewable Swiss power supply. Appl Energy 2017;192:1-11. http://dx.doi.org/10.1016/j.apenergy.2017.01.085.

[52] Torres JL, García A, Prieto E, de Francisco A. Characterization of wind speed data according to wind direction. Sol Energy 1999;66:57-64.

[53] Shoaib M, Siddiqui I, Amir YM, Rehman SU. Evaluation of wind power potential in Baburband (Pakistan) using Weibull distribution function. Renew Sust Energ Rev 2017;70:1343-51. http://dx.doi.org/10.1016/ j.rser.2016.12.037.

[54] Kantar YM, Usta I, Arik I, Yenilmez I. Distributions of wind speed at different heights. In: Proceedings - 2016 international conference on engineering and MIS. ICEMIS; 2016, 7745320. http://dx.doi.org/10.1109/ICEMIS.2016.7745320.

[55] Nedaei M, Ataei A, Adaramola MS, Mirzahosseini AH, Khalaji Assadi M, Assareh E. Comparative analysis of three numerical methods for estimating the onshore wind power in a coastal area. Int J Ambient Energy. http://dx.doi. org/10.1080/01430750.2016.1237890 [in press].

[56] Jovic S, Anicic O, Pejovic B. Management of the wind speed data using adaptive neuro-fuzzy methodology. Flow Meas Instrum 2016;50:201-8. http://dx.doi.org/10.1016/j.flowmeasinst.2016.07.002.

[57] Benmemdejahed M, Mouhadjer S. Evaluation of wind energy cost and site selection for a wind-farm in the south of Algeria. In: AIP conference proceedings; 2016. p. 1758, 020021. http://dx.doi.org/10.1063/1.4959397.

[58] Soltani N, Fazelpour F. Evaluation of wind energy potential and economics for the city of Kahnuj in Kerman Province, Iran. In: EEEIC 2016-international conference on environment and electrical engineering; 2016, 7555640. http://dx.doi.org/10.1109/EEEIC.2016.7555640.

[59] Sarkar A, Gugliani G, Deep S. Weibull model for wind speed data analysis of different locations in India. KSCE J Civ Eng. http://dx.doi.org/10.1007/s12205017-0538-5 [in press].

[60] Allouhi A, Zamzoum O, Islam MR, Saidur R, Kousksou T, Jamil A, et al. Evaluation of wind energy potential in Morocco's coastal regions. Renew Sust Energ Rev 2017;72:311-24. http://dx.doi.org/10.1016/j.rser.2017.01.047.

[61] JRC wind energy status report: 2016 edition. 2017 [Accessed 14 June 2017], https://ec.europa.eu/jrc/en/news/jrc-wind-energy-status-report-2016edition.

[62] Serrano-González J, Lacal-Arántegui R. Technological evolution of onshore wind turbines-a market-based analysis. Wind Energy 2016;19:2171-87. http://dx.doi.org/10.1002/we.1974.

[63] Premono BS, Tjahjana DDDP, Hadi S. Wind energy potential assessment to estimate performance of selected wind turbine in northern coastal region of Semarang-Indonesia. In: AIP conference proceedings; 2017. p. 1788, 030026. http://dx.doi.org/10.1063/1.4968279.

[64] Vasel-Be-Hagh A, Archer CL. Wind farm hub height optimization. Appl Energy 2017;195:905-21. http://dx.doi.org/10.1016/j.apenergy.2017.03.089.

[65] Baseer MA, Meyer JP, Rehman S, Alam MM. Wind power characteristics of seven data collection sites in Jubail, Saudi Arabia using Weibull parameters. Renew Energy 2017;102:35-49. http://dx.doi.org/10.1016/j.renene. 2016.10.040.

[66] Akpinar EK, Akpinar S. An assessment on seasonal analysis of wind energy characteristics and wind turbine characteristics. Energy Conv Manag 2005;46: 1848-67. http://dx.doi.org/10.1016/j.enconman.2004.08.012. 
[67] Silva dos Santos AT, Santos e Silva CM, Faro do Amaral Lemos D, de Lima Oliveira L, André Cruz Bezerra L. Assessment of wind resources in two parts of Northeast Brazil with the use of numerical models. Meteorol Appl 2016;23: 563-73. http://dx.doi.org/10.1002/met.1595.

[68] Islam KD, Dussadee N, Chaichana T. An approach to determine the Weibull parameters and wind power analysis of Saint Martin's island, Bangladesh. In: MATEC web of conferences; 2016. p. 70, 09004. http://dx.doi.org/10.1051/ matecconf/20167009004.

69] NREL, http://www.nrel.gov/gis/wind_detail.html; 2017 [Accessed 14 June 2017].

[70] Li C, Liu Y, Li G, Li J, Zhu D, Jia W, et al. Evaluation of wind energy resource and wind turbine characteristics at two locations in China. Technol Soc 2016;47: 121-8. http://dx.doi.org/10.1016/j.techsoc.2016.09.003. 